\title{
The Design Powers System: Cultivating Design Comperencies in Collaborative Endeavors
}

DENIELLE EMANS ${ }^{1}$ AND BASMA HAMDY ${ }^{2}$

1. Virginia Commonwealth University School of the Arts in Qatar, Education City, Doha, Qatar

2. Virginia Commonwealth University School of the Arts in Qatar, Education City, Doha, Qatar

SUGGESTED CITATION: Emans, D., \& Hamdy, B. "Design Powers: Cultivating Design Competencies in

Collaboration.” Dialectic, 2.1 (2018): pgs. 171-198. DOI: http://dx.doi.org/10.3998/dialectic.14932326.0002.108

\section{Abstract}

This piece begins with the authors' contention that design education must challenge design students to reframe their negative assumptions about teamwork in preparation for collaborations with future colleagues and communities who operate knowledge bases outside of the contexts established for and by designers. Guided by constructive-developmental pedagogy, ${ }^{\mathbf{a}}$ this case study report recounts a series of undergraduate graphic design courses taught by the authors over a three-year period, along with a secondary analysis of literature on mechanisms of collaboration in both vocational and educational contexts. A constructive-developmental paradigm suggests that undergraduate design students (and undergraduate students from other disciplines) can develop critical thinking and sophisticated problem-solving skills by first constructing a deep, broadly informed understanding of self. The authors propose a model to guide undergraduate design students toward self-discovery based on observable personality traits which they have chosen to refer to as Design Powers. By identifying their individual personality traits and creative motivations, young designers can learn to work productively in teams that value meaningful input from diverse personalities.

According to the authors, a Design Power is a design personality profile based on what motivates individuals to produce, create, and engage in design. Inspired by American psychologist David Keirsey's idea of the integrated whole, ${ }^{\mathbf{b}}$ the authors' investigate design personalities by looking at the creative preferences of an emerging designer as a whole, rather than according to independent scales or personality aspects, much like the Myers-Briggs method of personality assessment (also known as the Myers-Briggs Type Indicator). ${ }^{\mathbf{c}}$ Grouped under four distinct design profiles by the authors - Tinkerer, Dreamer, Storyteller, or Conductor - the reduction of the personality assessment of given graphic design students to one of these four personality profiles serves to promote self-awareness, rather than diminish, the complexity of individuals. 
An outgrowth of this research is the Design Powers System, which consists of three learning activities that progressively increase in complexity and structure as they are operationalized at the undergraduate level. These activities celebrate the value of self-discovery in university-level design classrooms and encourage young designers to work in teams comprised of members who possess complementary personality profiles during team-based activities. The findings from the author's three-year study of undergraduate graphic design courses they have taught suggest that groups composed of members who possess varying design acuities (as opposed to teams composed of comparably minded individuals) helps to create and sustain the functionalities of more temporally efficient, conceptually effective, and harmonious teams.

\section{keywords:}

\section{Collaboration, Design Education,}

Personality Traits, Teamwork

a "Constructive-developmental pedagogy is predicated on the idea that effective learning occurs within learning contexts, or developmental conditions, that have been created specifically to allow a given group of students to generate their own ideas and "find their own voices." Excerpted from Baxter Magolda, M.B. Making Their Own Way: Narratives for Transforming Higher Education to Promote Self-Development. Sterling, VA, USA: Stylus Publishing, 2004: pgs. 7-12.

b David Keirsey's theory defines four integrated configurations of personality or temperaments. These are: Artisan, Guardian, Idealist, and Rational. He describes temperaments as a "configuration of observable personality traits, such as habits of communication, patterns of action, and sets of characteristic attitudes, values, and talents." For more information on Keirsey's theory, the authors suggest the following reference: Keirsey, D. Please
Understand Me: Temperament, Character, Intelligence. Del Mar, CA, USA: Prometheus Nemesis Book Company, 1984.

c The Myers-Briggs Type Indicator (MBTI) is a personality inventory that maps four basic dimensions of human personality along a spectrum of extraversion/introversion, sensing/ intuition, thinking/feeling, and judging/perceiving. Consisting of a matrix of 16 personality traits determined by these four dimensions, the resulting variations are attributed to judgment and perception. The MBTI uses preferences as a primary indicator of the personality types and is not meant to assess traits, abilities, or character. For more information about the MBTI, the authors suggest the following reference: Briggs Myers, I. The Myers-Briggs Type Indicator: Manual. Palo Alto, CA, USA: Consulting Psychologists Press. 1962. 


\title{
The Design Powers System:
}

\author{
Cultivating Design Competencies in Collaborative Endeavors
}

DENIELLE EMANS \& BASMA HAMDY

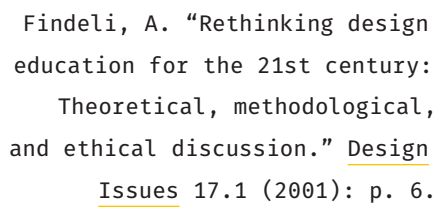

Davis, M. et al. "AIGA Designer 2025: Why Design Education Should Pay Attention to Trends," AIGA Design Educators Community, 22 August, 2017. Online. Available at: https:// educators.aiga.org/wp-content/uploads/2017/08/DESIGNER-2025-SUMMARY. pdf (Accessed 4 February 2018).

$\mathrm{d}^{\mathrm{d}}$ Throughout vocational and academic literature, the terms 'sole creator,' and 'lone genius,' refer to the accepted belief by business and creative leaders that innovation is the product of a single genius rather than the work of a collaborative and diverse group of people. Sawyer, $\mathrm{k}$. Group Genius: The Creative Power of Collaboration. New York, NY, USA: Basic Books, 2008, p. 5.

' The authors define 'team-thinking' as a collective cognitive ability to process information and problem-solve complex tasks within a team-based setting. As for the term 'shared project development,' it is the ability to apply methods, skills and knowledge to achieve a set goal.

\section{Introduction}

The nineteenth and early twentieth-century model of design education was primarily guided by the need to satisfy mandates from rapidly upscaling economic and industrial forces. ${ }^{1}$ Business plans and entrepreneurial activities attached to design processes celebrated the 'sole creator,' d and were structured to undervalue the efforts of team thinking and shared project development . ${ }^{e}$ Similarly, educational institutions that taught design at the university level placed great emphasis on "the illusion of original creativity," which involved students learning to generate outcomes to design processes largely in service to an individual organization's economic success and material progress. ${ }^{2}$ While the so-called function and intention of the design process has evolved significantly over the course of the last century to teach students to effectively engage in collaborative endeavors that benefit communities, influence public policies or positively alter ways of doing and making, some educators continue to perceive the social, economic and cultural role of the designer as constrained to delivering messages and products. ${ }^{3}$

Recent directions in design practice point toward a more pluralistic discipline characterized by a need to develop more responsive social, environmental, and cultural protocols. ${ }^{4}$ The First Things First manifesto-originally published by Ken Garland in $1964^{5}$ and re-published in the 51st issue of Emigre as the First Things First 2000 manifesto in 1999-calls for "a reversal of 
5

Garland, K. "First Things First,"

The Guardian, 29 November 1963. Online. Available at: http://www.designishistory.com/1960/first-things-

first/ (Accessed March 20, 2018).

6

BarnbTook, J. et al. "First Things

First Manifesto 2000." AIGA Journal of Graphic Design, 17 (1999): p. 2.

\section{7}

Buchanan, R. “Human-centered design: Changing perspectives on design education in the East and West." Design Issues, 20.1 (2004): p. 35.

8

Katzenbach, J. \& Smith, D. The Wisdom of Teams. Boston, MA, USA: Harvard Business Review Press, 2015, p. 41.

\section{9}

Sawyer, K. Group Genius: The Creative Power of Collaboration. New York, NY, USA: Basic Books, 2008, p. 17.

10

Gratton \& Erickson, "Eight Ways to Build Collaborative Teams." Harvard Business Review, (November 2007): 43. Online. Available at: https://hbr.org/2007/11/eightways-to-build-collaborative-teams (Accessed May 12, 2017).

\section{1}

Ibid., p. 43-44.

12

Buchanan, R. “Human-centered design: Changing perspectives on design education in the East and West." Design Issues, 20.1 (2004): p. 35 . priorities in favor of more useful, lasting and democratic forms of communication... a mindshift away from product marketing and toward the exploration and production of a new kind of meaning." " In alignment with the first First Things First 2000 manifesto, this study advocates for the potential of operationalizing design's diverse and broadly informed human resources, and the visual languages that these fuel, to support group productivity (in lieu of a competitive mindset), and promotes the creation of artifacts, systems and experiences that meet real (and sustainable) human needs and goals.

One tranche of design-related research suggests that a collaborative, team-based approach is necessary to guide the development of more economically and environmentally resilient ways of making that extend to public policy and social development. ${ }^{7}$ If productivity, project development, and innovation are to be improved, the complexity of working in these environments not only necessitates teamwork, but disciplinary and cultural diversity among team members. ${ }^{8-12}$ In light of this, visual communication design education must at least begin to transform its essential practices so that students learn to effectively sustain collaborations with colleagues in disciplines outside design, work with people from communities and cultures beyond their established context, and engage in creative dialogue - rather than compete-with people who have not attended design school. ${ }^{13,14}$

\section{How Competition and Individualism Affect Group Efforts}

One day a hare was bragging about how fast he could run. He bragged and bragged about his speed, and even laughed at the tortoise, who was quite slow by comparison (The Tortoise and the Hare by Aesop).

In tandem with the need for commercial visual communication design practices to generate economically and environmentally resilient ways of making, moderate to extreme levels of competition among individuals in the workplace can strangle productivity, professional development, and most importantly, team-building. ${ }^{14}$ There have recently been several calls from prominent design educators and researchers for visual communication design education to reassess approaches that entail teaching so many students to work in competition-driven learning environments that stress individual achievement over team-based initiatives and projects. ${ }^{15-17}$ Despite these 
${ }^{\mathrm{f}}$ For a description of this term see note no.4 on 'sole creator' or 'lone genius.'

13

Gibson, M.R. \& Owens, K.M. "Making meaning happen between 'us' and 'them': strategies for bridging gaps in understanding between researchers

who possess design knowledge and those working in disciplines outside design." In The Routledge Companion to Design Research, edited by J. Yee and P. Rodgers, pgs. 386-399. Routledge, NY, NY, USA: 2015.

14

Rock, D., Davis, J. \& Jones, B. "Kill Your Performance Ratings." Strategy+Business, 8 August, 2014, 76 (2014). Online. Available at: http://www.strategy-business.com/ article/00275?gko=c442b (Accessed July 19, 2017).

\section{5}

Heller, S. \& Talarico, L., “Education Manifesto" in Icograda Design Education Manifesto, Taipei: International Council of Graphic Design

Associations, edited by Audrey Bennett \& Omar Vulpinari, 11 October 2011: p. 84. Online. Available at: http://www.ico-d.org/database/files/

library/IcogradaEducationManifesto_2011.pdf (Accessed May 12, 2017).

\section{6}

Hunt, J. "Education Manifesto" in Icograda Design Education Manifesto, Taipei: International Council of Graphic Design Associations, edited by Audrey Bennett \& Omar Vulpinari, 11 October 2011: p. 88. Online. Available at: http://www.ico-d.org/ database/files/library/Icograda EducationManifesto_2011.pdf (Accessed May 12, 2017).

\section{7}

Friedman, K. “Models of Design: Envisioning a Future Design Education." Visible Language, 46.1/2 (2012): p. 143 . entreaties, contemporary design classrooms the world over nurture cultures of student-versus-student competition as instructors perpetuate the creation of 'portfolio-worthy' projects designed by individual students. These tend to celebrate the assumption of the so-called 'one-size-fits-all designer,' or the 'lone genius ' ${ }^{f}$ model of designing. The perpetuation of these approaches may be rooted in inherited (but seldom questioned) educational frameworks wherein faculty recycle curricula based on the residing belief that students should be designing to meet the needs and goals of what is (or was) primarily a service economy. Traditional quantitative grading systems also contribute to the perpetuation of competitive spaces in design classrooms, often rewarding the brightest, loudest and most aggressive of students. Much like the hare in Aesop's tale, celebrating the fastest individual rewards the assertion of one facet of an emerging designer's personality, but simultaneously stifles the potential of alternative modes of engagement such as those planned and operationalized by the slow and purposeful tortoise.

David Rock, a leading proponent of combining neuroscience with leadership, describes five domains affecting the human brain during social experience and interaction as part of his neuroscience-based model, SCARF (Status, Certainty, Autonomy, Relatedness and Fairness). In particular, the 'status' factor can contribute to an individual's superiority complex and potential threat response. "Winning a swimming race, a card game or an argument probably feels good because of the perception of increased status and the resulting reward circuitry being activated. The perception of a potential or real reduction in status can generate a strong threat response." ${ }^{18}$ Contrary to popular corporate strategies, workplace research suggests that competition is an impediment to development, with performance management systems often failing to motivate or aid the development of employees. These types of performance systems tend to generate a negative neural response and significantly retard efforts among individuals to collaborate by devaluing the role of each individual in a group. ${ }^{19}$ Competitive mindsets have also been shown to leave individuals ill-prepared to navigate the complexities of team-based collaboration in these same firms.

\section{Facilitating Effective Collaboration and Teamwork}

A Lion used to prowl about a field in which four oxen used to dwell. Many a time he tried to attack them, but whenever he came near they turned 


\section{8}

Rock, D. "SCARF: A Brain-

Based Model." NeuroLeadership, 1.1 (2008): pgs. 46.

19

Rock, D., Davis, J. \& Jones, B. “Kill Your Performance Ratings." Strategy+Business, 8 August, 2014, 76 (2014). Online. Available at: http://www.strategy-business.com/ article/00275? gko=c442b (Accessed July 19, 2017).

\section{0}

Rosen, E. The Culture of Collaboration. San Francisco, CA, USA: Red Ape Publishing, 2007: p. 9.

21

Patton, B.R. \& Downs, T.M. Decision-Making Group Interaction: Achieving Quality, 4th Edition. Boston, MA, USA: Pearson, 2002: p. 2.

\section{2}

Katzenbach, J. R. \& Smith, D.K. The Wisdom of Teams, New York, NY, USA: Harper Business, 2006: p. 41.

\section{3}

Sawyer, K. Group Genius. New York, NY, USA: Basic Books, 2017: p. 17.

24

Gratton, L. \& Erickson, T.J. "Eight Ways to Build Collaborative Teams." Harvard Business Review, 85.11 (2007): 101-109. Online. Available at: http://morris.lis.ntu. edu.tw/KM2016/wp-content/uploads/KM/ W14-1GrattonErickson2007.pdf (Accessed February 9, 2018).

\section{5}

Sawyer, K. Group Genius. New York, NY, USA: Basic Books, 2017: p. 17.

26

Ibid., p. 43-44. their tails to one another, so that no matter which way he approached them, he was met by a set of horns (The Four Oxen and the Lion by Aesop).

In the context of this discourse, collaboration describes a situation within which a group of people with complementary skills and bases of knowledge (who make use of various modes and styles of communication) work together toward achieving a common goal. Collaboration and communication strategist Evan Rosen defines collaboration as "[any group of people] working together to create value while sharing virtual or physical space." ${ }^{20}$ Bobby Patton and Timothy Downs - researchers on interpersonal and small group communication-similarly define "group-work" as a process involving a small number of individuals, in interdependent roles, utilizing various forms of communication to act as a single unit working towards a collective goal. ${ }^{21}$ In their book The Wisdom of Teams, Jon Katzenbach and Douglas Smith (both are authorities on organizational culture and leadership in business) describe a 'high-performance' team as a small number of people with complementary skills. ${ }^{22}$ Regardless of the terminology, research indicates that group productivity and project development is improved when teams possess complementary skills, diverse communication styles, and group flow. ${ }^{23,24}$ The idea of group flow grew out of psychological studies of and about why and how collaborative teams - such as writing groups, sports teams and musical ensembles - experience a heightened sense of focus and creativity as they collectively engage in a goal-oriented activity or set of activities in ways that make the individuals in the group less self-conscious.

Keith Sawyer, a Professor of Educational Innovations at the University of North Carolina at Chapel Hill (U.S.) and a leading scientific expert on creativity, innovation and learning, suggests 'improvisation' is the fundamental building block of effective collaboration. In his book, Group Genius: The Creative Power of Collaboration, Sawyer emphasizes the importance of brainstorming within organizational hierarchies that encourages free-flowing improvisational approaches and mindsets to guide the process. In this manner, brainstorming enables teams to build from one idea to the next, with shared ideas prompting new insights. ${ }^{25}$ Sawyer also argues that group flow plays a significant role in collaborative activities, with peak group performance driven by members who, simultaneously, reach optimal levels of creativity together. ${ }^{26}$ A unique and essential component of group flow (or shared creative inspiration) is the necessity to configure teams by members who possess varying 
communication styles, rather than teams composed of individuals who all communicate in a similar manner.

"If everyone functions identically and shares the same habits of communicating, nothing new and unexpected will ever emerge because group members don't need to pay close attention to what the others are doing, and they don't continually have to update their understanding of what is going on.” 27

Sawyer's view of improvisation and communication challenges traditional opinions about group dynamics wherein teams ideally possess identical communication styles. These dynamics likely arose from organizational communication practices that were commonly operationalized during the industrialization era. During this time period, vertically-oriented hierarchical systems divided roles between disparately ranked members within an organization. ${ }^{28}$ This well-established operational modality required focused, parallel commu-

Friedman, K. “Models of Design: Envisioning a Future Design Education." Visible Language, 46.1/2 (2012): p. $140-41$.

Katzenbach, J. R. \& Smith, D.K. The Wisdom of Teams, New York, NY, USA: Harper Business, 2006: p. 41. 31

Gratton, L. \& Erickson, T.J. "Eight Ways to Build Collaborative Teams." Harvard Business Review, 85.11 (2007): 101-109. Online. Available at: http://morris.lis.ntu.edu. tw/KM2016/wp-content/uploads/KM/ W14-1GrattonErickson2007.pdf (Accessed February 9, 2018).

Katzenbach, J. R. \& Smith, D.K. The Wisdom of Teams, New York, NY, USA: Harper Business, 2006: pgs. 47-8. nication styles to produce goods in assembly line systems. In other words, individuals within a group would divide the workload by focusing on the same task in analogous paths. Similarly, the modes and methodologies of professional design during the industrialization era also served a trade-based economy based on division of labor and empiricism.

In the post industrialization era, the principles underlying design practice shifted - to one defined in much of the literature as a knowledge-based economy of networked labor and systems thinking. ${ }^{29}$ In these cases, teams began to tackle multifaceted challenges with group members of varied skills and intelligences together, rather than dividing the labor. ${ }^{30}$ Writing in 2007 in the Harvard Business Review, business educators and researchers Lynda Gratton and Tamara Erickson promote the importance of working in diverse business teams to grow ideas together, noting that including people who possess disparate backgrounds and views enable "cross-fertilization that sparks insight and innovation." ${ }^{31}$

By interviewing hundreds of individuals across a range of organizations, business management authors Jon Katzenbach and Douglas Smith associate 'high-performance' teams with a combination of both functional and technical proficiencies, including problem-solving and interpersonal communication. ${ }^{32}$ Similar to the four oxen who work together to protect themselves against the lion, high performance teams achieve success when they are equally 


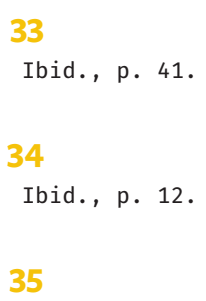

Keirsey, D. Please Understand Me: Temperament, Character, Intelligence. Del Mar, CA, USA: Prometheus Nemesis Book Company, 1984: p. 17.

36

Richardson, R.C. \& DeVaney, T.A. "Personality Instrument to Increase Collaboration." Educational Research and Reviews, 3.4 (2008): pgs. 121-127.

37

Ibid., p. 123 .

38

Turner, J., Oakes, P., Haslam, S.,

\& McGarty, C. "Self and Collec-

tive: Cognition and Social Context."

Personality and Social Psychology Bulletin, 20.5 (1994): pgs. 454-463. committed to a common purpose. Katzenbach and Smith go on to say that teams built with complementary skills invest in the personal growth of one another by holding themselves mutually accountable for the success of the group. ${ }^{33}$ This kind of group-work encourages team-members to become flexible and responsive to change by establishing trust, defining goals, and building confidence in a project together. ${ }^{34}$

\section{Identifying how Personality Types and Complementary Skills Affect Teamwork}

Once upon a time in the Land of $\mathrm{Oz}$, four individuals set out on a strange and dangerous journey. Each of them was lacking something vital to his or her nature, and each wanted to find the great $\mathrm{O} z$ and ask him for help. ${ }^{35}$

Inasmuch as research suggests complementary skills are necessary for effective teamwork, personality types also play a meaningful role in group interactions. Identifying individual preferences can provide insight into worldviews, inspirations, problem-solving approaches, and most importantly, group dynamics. Studies have determined that personality identification is also useful in developing interpersonal growth because it confirms individual value and contribution to the group. ${ }^{36}$

With the ancient study of temperaments tracing as far back as Plato and Hippocrates, recognizing variations among people is by no means a new or groundbreaking concept. ${ }^{37}$ Briefly stated, temperament accounts for how an individual's combination of mental, physical and emotional characteristics affects their behavior. Several theories of cognitive psychology suggest that the brain is wired to classify and categorize semantically as a way to protect ourselves and make decisions quickly in threat situations. Self-categorization theory suggests that individuals tend to perceive themselves - and others - as belonging to particular groups. Even further, group properties or characteristics tend to shift self-perception from personal to social identity. ${ }^{38}$

Within the psychology community, Carl Jung remains a prominent and influential figure due to his extensive research in the area of analytical psychology. His theory of psychological types, developed in 1921, was guided by the notion that humans experience four mental functions: sensation, intuition, feeling, and thinking. In 1962, Katharine Briggs, and her daughter Isabel Briggs Myers, adapted his theory to produce the Myers-Briggs Type Indicator (MBTI). 
Tieger, P., Barron, B., \& Tieger, K. Do What You Are: Discover the Perfect Career for You Through the Secrets of Personality Type. New York, NY, USA: Little, Brown and Company, 2014: pgs. 12-13. 40

Winterhalter, B. “ISTJ? ENFP? Careers Hinge on a Dubious Personality Test." The Boston Globe, 31 August 2014. Online. Available at: http://www. bostonglobe.com/ opinion/2014/08/30/istj-enfp-careers-hinge-dubious-personality-test/8ptUGXhu6DndFdjCngcxSN/story.html (Accessed January 19, 2017).

\section{1}

Tieger, P., Barron, B., \& Tieger, K. Do What You Are: Discover the Perfect Career for You Through the Secrets of Personality Type. New York, NY, USA: Little, Brown and Company, 2014: p. 5.

42

Keirsey, D. Please Understand Me: Temperament, Character, Intelligence. Del Mar, CA, USA: Prometheus Nemesis Book Company, 1984: pgs. 17-18.

Ibid: p. 31.
In the following years, the MBTI was further modified by various psychologists and continues to serve as a primary indicator of personality variation.

The MBTI involves identifying four basic dimensions of human personality along a spectrum of extraversion/introversion, sensing/intuition, thinking/feeling, and judging/perceiving. Consisting of a matrix of 16 personality traits, determined by these four dimensions, the resulting variations are attributed to judgment and perception. ${ }^{39}$ Over the past decade, the MBTI was used by approximately $80 \%$ of Fortune 500 companies as a scientific measure to ensure employees were placed in the correct roles or to help teams work together. ${ }^{40}$ Furthermore, the authors of the book, Do What You Are argue that millennials will achieve greater job satisfaction if they can identify a profession that will accommodate their MBTI personality preferences. ${ }^{41}$

In Please Understand Me II, David Keirsey discusses the recurrence of the number four when looking at personality patterns in humans. Heavily influenced by Myers' indicators, Keirsey poetically relates the recurring number four in personality traits to the classic children's book The Wizard of Oz, highlighting how these distinct differences have been identified in people for thousands of years. ${ }^{42}$ Consequently, his theory, which is inspired and influenced by ancient and historical theories of temperaments, also outlines four configurations. Keirsey defines temperament as a "configuration of observable personality traits, such as habits of communication, patterns of action, and sets of characteristic attitudes, values, and talents." Building on Plato's description of personality types, Keirsey defines the four integrated configurations of personality, or temperaments as Artisan, Guardian, Idealist, and Rational. He relates his perspective to that of "organismic wholism," wherein personality traits develop through differentiation, similar to cells in the body. ${ }^{43}$ If varying personality traits begin with an integrated whole, then the need to identify variations in humans is a logical starting point to produce a harmonious group.

The authors of this piece propose that contemporary design education programs can benefit from this line of research in psychology to help students identify their individual personality traits and prepare them to work productively in teams that value personality diversity. The conventional teaching approach, one that measures students as identical contenders in an assessment race, contradicts major studies in both psychology and collaboration that emphasize the importance of diversity within business teams. Furthermore, research demonstrates how multifaceted challenges are often solved by teams who possess varied skills and intelligences. 
44

Kolko, J. Wicked Problems: Problems Worth Solving: A Handbook \& A Call to Action. Austin, TX, USA: ac4d, 2012.

\section{5}

Armstrong, H., Blume, M., Chochinov, A., Davis, M., Dubberly, H., Kincaid, K., Lee, J., Irwin, T., Pangaro, P., Stillion, D., Yap, M. "The Designer of 2025: Why Design Education Should Pay Attention to Trends." AIGA, 22 August, 2017. Online. Available at: https:// educators.aiga.org/wp-content/uploads/2017/08/DESIGNER-2025-SUMMARY.pdf (Accessed March 10, 2018).

Peeters et al., "Design Behavior Questionnaire for Multidisciplinary Teams." Design Studies, 28.6 (2007): pgs. 623-643.

$\mathrm{g}$ Acuity-based team creation is defined by the authors as a process involving the identification of dominant skill-based acuities in order to create diverse, yet, synergetic teams.

${ }^{\mathrm{h}}$ Wicked problems are complicated social or cultural issues that cannot be completely described or solved in traditional linear methods because each problem is a symptom of another problem. There are a number of reasons why wicked problems are difficult to solve, including large economic burdens, incomplete or contradictory knowledge, and the involvement of numerous people and opinions in the social challenge. For more information about Wicked Problems, the authors suggest the following reference: Kolko, J. Wicked Problems: Problems Worth Solving: A Handbook \& A Call to Action. Austin, TX, USA: ac4d, 2012, and Buchanan, R. "Wicked Problems in Design Thinking." Design Issues, 8.2 (1992): pgs.: 5-21.

\section{Examining the Research Opportunity in the Design Powers}

\section{System and the Methodology that Guided its Development}

Recent scholarship from design suggests the need for emerging designers, design educators and scholars to learn to work more effectively in teams. The capacity to learn how to think and work empathetically as part of a collaborative working group is particularly meaningful as initiatives such as design for good, design for democracy, and design for social change continue to gain traction. In his handbook An Introduction to Wicked Problems, Jon Kolko explains that an essential aspect of beginning to address social or cultural problems involves learning to work collaboratively across disciplines. ${ }^{44}$ More recently, the team of authors who created the future-focused missive The AIGA Designer of 2025 offered that, “...systems today... are built on models of conversation in which power is shared and content develops collaboratively and organically." 45 Opining from these perspectives, it is essential to equip emerging designers with the skills and bases of knowledge necessary to help them communicate and collaborate with colleagues in disciplines outside design.

Numerous studies explore the benefits and applications of collaboration in design classrooms; ${ }^{46-47}$ however, few studies articulate effective procedural approaches to facilitate acuity-based team creation. ${ }^{g}$ Additionally, little research exists on the relationships between collaboration and identifying personality traits in the context of design education. This gap in research suggests an opportunity to contribute to the scholarly literature in and around this area by working with design students to ascertain which of their skill-based competencies might most effectively fuel collaborative methodologies in and outside design classrooms, as well as prepare them for engaging in the coordination of complex projects that respond to socially or culturally specific problems.

Traditional approaches and processes of teamwork fall short of fully addressing the dynamic nature of design ${ }^{49}$ and wicked problems ${ }^{\mathrm{h}}$ in which there are a wide variety of complexities that make definitive and objective outcomes to design processes impossible to achieve. Building self-awareness coupled with respect for perspectives different from one's own is necessary if design students are to effectively engage with people from communities and cultures outside of their established contexts of work or understandings, especially if these people have not attended design school. This involves developing the capacity of a designer to be emotionally open enough to move outside of hisor-her psychological comfort zone to at least partially embrace logical and conceptual ambiguity as situations demand. 
47

Dong, Kleinsmann \& Deken, "Investigating Design Cognition." Design Studies, 34.1 (2013): pgs. 1-33.

\section{8}

Van Leeuwen, van Gassel \& den

Otter, "Teaching Collaborative Design." In Proceedings of the International Workshop on Construction Information Technology in Education, 7 September 2004 Istanbul, Turkey, 2004: pgs. $1-9$. 49

Armstrong, H., Blume, M., Chochinov, A., Davis, M., Dubberly, H., Kincaid, K., Lee, J., Irwin, T., Pangaro, P., Stillion, D., Yap, M. “The Designer of 2025: Why Design Education Should Pay Attention to Trends." AIGA, 22 August, 2017. Online. Available at: https:// educators.aiga.org/wp-content/uploads/2017/08/DESIGNER-2025-SUMMARY. pdf (Accessed February 4, 2018).

50

Katzenbach, J., \& Smith, D. The Wisdom of Teams: Creating the High-Performance Organization. New Boston, MA, USA: Harvard Business Review Press, 2015.

51

Rosen, E. The Culture of Collaboration: Maximizing Time, Talent and Tools to Create Value in the Global Economy. San Francisco, CA, USA: Red Ape Publishing, 2007.

52

Sawyer, K. Group Genius: The Creative Power of Collaboration. New York, NY, USA: Basic Books, 2008.

53

Patton, B.R. \& Downs, T.M. Decision-Making Group Interaction: Achieving Quality, 4th Edition. Boston, MA, USA: Pearson, 2002: p. 2.
Like the four main characters in the Wizard of $\mathrm{Oz}$ using their combined powers to complete their journey, this study supports the notion that diversified design teams fuel high levels of innovation and invention. Building on Keirsey's idea of the integrated whole and the Myers-Briggs [Personality] Type Indicator (MBTI), along with theories of collaboration proposed by Katzenbach and Smith, Rosen, Sawyer and Patton, ${ }^{50-53}$ a preliminary model for team-based collaboration was developed for use in an undergraduate learning environment that could operationalize both the value of the individual talent - or power-of a given design student as well as his-or-her membership in a diversely populated team.

Over a period of three consecutive years (2014-2017), the Design Powers System was tested in four separate undergraduate graphic design classrooms consisting of an average of 20 students residing in Qatar. During this time, these design students participated in a series of activities and observations that challenged them to focus on self-reflection and self-identification to determine their dominant design profiles-Conductor, Storyteller, Tinkerer, or Dreamer (see Figure 2). These varied activities aimed to empower students to make meaningful contributions to group projects and celebrate their unique roles as integral contributors to design teams. Faculty observations and individual discussions were a necessary aspect of the data gathering and analysis process that informed this research, and helped inform the testing and evaluation of the Design Powers System and, ultimately, contextualize the resulting student feedback.

To manage and refine the collaborative processes, the two design faculty who facilitated this testing administered written assessment forms and engaged students in providing verbal feedback through open-ended discussions. Data was collected both during and after student immersions in learning experiences that were affected by the Design Powers System. Specifically, individual feedback was collected from each student using an anonymous short-answer questionnaire that functioned as a written assessment of each student's ability to achieve certain learning outcomes. The goal of the survey was to position the student's role within the collaborative team and to examine to what degree it confirmed or contradicted her/his identified competency.

\section{A Contextualized Description of the Four Dominant Design Profiles}

This research identifies four design dualities (see Figure 1), presented as continuums, that are inspired by the Meyer Briggs [Personality] Type Indicator's four 


\begin{tabular}{|c|c|}
\hline REASON $=$ INTUITION & EMPATHY $=$ PRAGMATISM \\
\hline $\begin{array}{l}\text { Reason-based designers focus on facts to make } \\
\text { objective decisions. They are practical, detail-oriented } \\
\text { and excellent at detecting flaws in various project } \\
\text { components. They build on real-life experiences and } \\
\text { dislike speculation or information that is not verified. } \\
\text { They prefer controlled work environments and enjoy } \\
\text { following step-by-step instructions to learn new skills. } \\
\text { Intuition-based designers do not accept the status } \\
\text { quo and often think about alternative directions and } \\
\text { possibilities. They tend to be imaginative and discover } \\
\text { opportunities for improvement by establishing new } \\
\text { design trends and patterns. They normally prefer to } \\
\text { 'feel-out' new territory and tend to avoid step-by-step } \\
\text { instructions to learn new skills. }\end{array}$ & $\begin{array}{l}\text { Empathetic designers are diplomatic and tactful } \\
\text { individuals. They are highly considerate of how people } \\
\text { feel and give more weight to principles over professional } \\
\text { success. They are emotional, compassionate and care } \\
\text { deeply about how people see them. They are sensitive } \\
\text { and promote harmony in the world around them. When } \\
\text { dealing with people, they find it difficult to be brutally } \\
\text { honest and can sometimes be too idealistic. } \\
\text { Pragmatic designers tend to be analytical, and rely on } \\
\text { facts and experience to make decisions. They are quick } \\
\text { to shut down ideas that seem illogical, far-fetched or } \\
\text { unrealistic and prefer to carefully plan and structure } \\
\text { projects. Designers who are more pragmatic tend to } \\
\text { approach design decisions from a detached standpoint } \\
\text { using logic and reason to come to a conclusion. When } \\
\text { collaborating with others, they prefer to be honest rather } \\
\text { than tactful or diplomatic. }\end{array}$ \\
\hline CONCRETE $=$ ABSTRACT & INTERNAL $=$ EXTERNAL \\
\hline $\begin{array}{l}\text { Concrete designers have a strict work-ethic and } \\
\text { like to adhere to rules and established codes. They } \\
\text { are excellent at organization, planning, and will always } \\
\text { have multiple backup plans. Designers who are more } \\
\text { concrete are excellent at making sure a project is } \\
\text { completed to the highest standard. They sometimes } \\
\text { miss seeing new or unexpected opportunities because } \\
\text { they are too focused on the task at hand. }\end{array}$ & $\begin{array}{l}\text { Internal designers are thought-oriented and more } \\
\text { sensitive to external stimulation. They prefer to isolate } \\
\text { themselves in order to be more productive. Internal } \\
\text { designers can get overwhelmed by an excess of sights } \\
\text { and sounds and would rather not take the lead in social } \\
\text { situations such as public speaking or presentations. } \\
\text { Their preference is to have less frequent, but more } \\
\text { meaningful interactions with those around them. }\end{array}$ \\
\hline $\begin{array}{l}\text { Abstract designers are excellent at discovering new } \\
\text { and unexpected connections through improvisation. } \\
\text { They are spontaneous, flexible and do not conform to } \\
\text { traditions, habits or societal norms. Designers who are } \\
\text { more abstract can be impulsive, rebelling against their } \\
\text { teachers, supervisors or managers. They sometimes } \\
\text { miss deadlines or may forget to complete tasks if they } \\
\text { are too focused on open-ended possibilities. }\end{array}$ & $\begin{array}{l}\text { External designers are action-oriented and seek } \\
\text { energy from their environment and the people around } \\
\text { them. They become energized with frequent interaction } \\
\text { and often take the lead during presentations or group } \\
\text { situations. They prefer to engage in many different } \\
\text { activities and feel most productive when expressing } \\
\text { themselves. Their preference is to connect horizontally, } \\
\text { creating a social network with all team-members. }\end{array}$ \\
\hline
\end{tabular}

FIGURE 1: This table depicts the four "design dualities," from which the dominant design traits depicted in Figure 2 are derived.

basic dimensions and the observable skilled-actions described by Keirsey. The four design dualities were extracted by the authors after extensive observation, discussion, and daily work with the undergraduate design students from Qatar. These dualities can be considered as building blocks that determine how a creative individual might operate in a collaborative group setting. If one trait becomes dominant on a given continuum, it can help to determine that design student's patterns of action, communication style, attitudes, and values as he-or-she engages in a specific design challenge. In this manner, the dominant design profile for that individual can be identified. Figure 1 articulates in-depth descriptions of the four design dualities: reason/intuition, empathy/pragmatism, concrete/abstract and internal/external.

The four design dualities described here produce four dominant traits of character, or design profiles. Mapping these dualities onto the Design Powers Wheel demonstrates how a given student designer's personality traits can be 
The Insights Discovery System builds on the work of Swiss psychologist C.G. Jung's attitude preferences (extraversion and introversion) and rational functions (thinking and feeling). From this foundation, a wheel diagram is used to help individuals identify areas for personal growth, along with organizational strengths and weaknesses when the data is collated with others' profiles. For more information on the Insights Discovery System, the authors suggest the following reference: "Comparison of Insights Discovery System to Myers-Briggs Type Indicator." pgs. 1-5. Online. Available at: http://www.inside-inspiration. com.au/factsheets/insights-discovery-and-mbti-comparison.pdf (Accessed May 12, 2017).

${ }^{\mathrm{j}}$ The Tilt Leadership Model is a scientifically validated development tool created by Pam Boney to guide leaders in the assessment of character-based strengths

to increase business productivity and innovation. For more information on the Tilt Leadership Model the authors suggest the following reference: Boney, P. True Tilt: An Uncommon Quest. Bloomington, IN, USA: Author House, 2010.

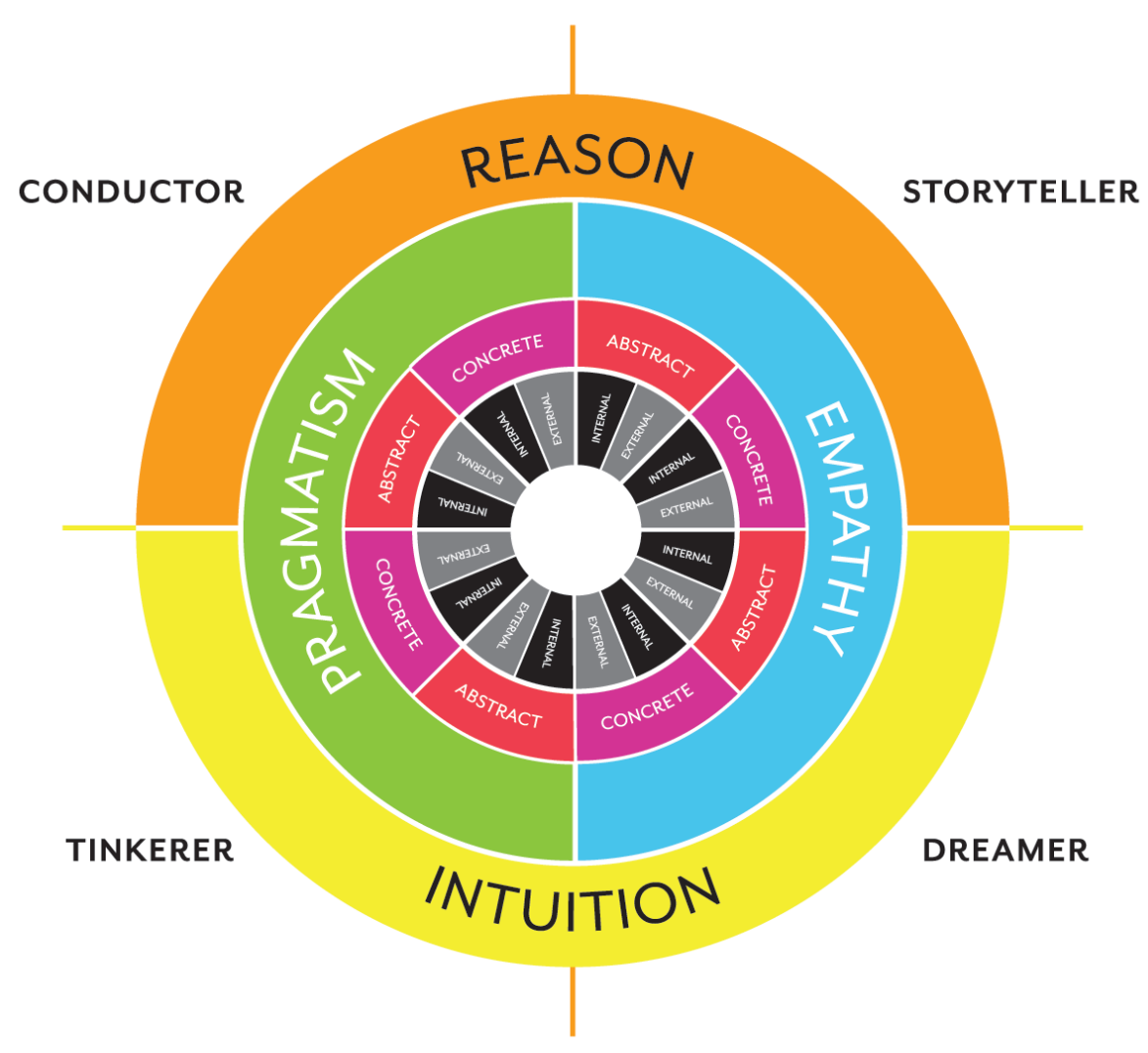

FIGURE 2: The Design Powers Wheel, which depicts how different personality traits exhibited by given design students are affected by their possession of or identification with particular, sometimes overlapping, values and competencies. These traits are integrated around portions of the circumference of the wheel - grouped into oppositional pairs called "dualities - to create four dominant design profiles.

integrated to produce the four dominant profiles (depicted in figure 2). The Design Powers Wheel was adapted primarily from the Myers-Briggs Type Indicator Model, the Insights Discovery Model ${ }^{i}$, and the Tilt Leadership Model ${ }^{\mathfrak{j}}$ to visually demonstrate how the spectrum of creative motivations relate to personality traits, behavioral patterns, strength-based assessments and other qualities. The Design Powers Wheel illustrates that designers may possess aspects of two competencies that lie along the same spectrum, but self-identify with one competency over the other (by choosing the one that best maps to their social, economic or cultural values and creative motivations). For example, a designer who identifies as empathetic may also be pragmatic at times, but still chooses to see empathy as a dominant value in their profile.

When presented in a design classroom, the four dominant design profiles are often best introduced by a faculty member who is conducting a 
Conductors are skilled leaders adept at problem solving. They possess strong organizational skills and enjoy managing discreet details throughout the design process. Similar to an orchestra conductor, these designers are skilled at encouraging teams to work harmoniously together by creating environments that support innovation and creativity.

With strong management skills, Conductors are driven by the excitement of guiding a group through a project's deliberate and strategic growth. They are detail-oriented and diligent, possessing a mastery of skills in communication, pragmatism, and assessment.

Tinkerers are natural risk-takers energized by new possibilities and eager to tackle the unknown. They are anxious to uncover new approaches and want to make ideas become a physical reality. With an eager sense of determination, they find confidence in mastering a new skill and naturally see how things work.

Tinkerers possess high technical mastery in both digital and hands-on applications with a focus on the tangible. Tinkerers are motivated to invent solutions and turn ideas into action by diving into the making process allowing mistakes to happen, and delighting in the results.
Storytellers are articulate orators adept at the visualization and articulation of outcomes. With empathetic and observational abilities, they can express design challenges, processes, and outcomes through compelling narratives. When others struggle to find the right words, Storytellers can say the right thing and strike the right tone.

Storytellers have an instinctive ability to describe, understand, and elaborate on the experiences of others. They can help express ideas to clients or team members and facilitate trust-building and communication. Storytellers acknowledge the value of debate and discussion, but ultimately believe that realistic ideas are what matter most.

Dreamers enjoy the possibility of the unknown and consider the future as an opportunity to stretch the boundaries of design ingenuity. With imaginations full of new possibilities, Dreamers are visionaries who fluently generate concepts with little pragmatic consideration.

Dreamers are ethical idealists striving to reach new heights through visions of a better product, intervention, or idea. They are hindered by real world restrictions and guided by emotional depth. They understand the importance of connecting with people and have a natural intuition for reading people's emotions.

FIGURE 3: The four dominant design profiles that result from allowing design students to operate the wheels that comprise the Design Powers System are described briefly here.

collaborative design project. This process involves asking students to choose one side of each duality (reason versus intuition; pragmatism versus empathy; etc.). The visual representation of the two sides of the wheel (reason/intuition and empathy/pragmatism) and the oppositional concepts embedded around the two inner circles of the wheel (concrete/abstract; external/internal) exist to highlight the importance of integrating each of the paired qualities into a given student's personal design process. This means that this particular student should not, for example, discount the importance of empathy, even when he-or-she prefers to engage in a more pragmatic approach to a specific design challenge. Additionally, the visibility of these creative motivations - as two sides of one wheel and equally distributed portions of two inner wheels - suggests the potential for an expansion of an individual student's personal growth by making him-or-her aware of qualities they might want to emphasize, hone, or improve in the future. For instance, if a student generally prefers to follow 
intuition as he-or-she engages in his-or-her design work, there may be an opportunity to follow reason as a way to expand their creative thinking in a forthcoming project.

The primary goal of this activity is for each student in the design classroom to self-identify with one of the four design profiles - Tinkerer, Dreamer, Storyteller, or Conductor - (Figure 3) to facilitate the composition of balanced design teams. The following example illustrates this self-identification process and demonstrates how a particular individual can engage with the Design Powers System.

Hypothetical student "Mary" chooses the personality trait 'reason' over 'intuition' on the Design Powers Wheel, as she is practical, detail-oriented and excellent at detecting flaws. She identifies with the personality trait 'empathy' over 'pragmatism' since she is emotional, compassionate and cares deeply about how people perceive her. She is 'abstract' rather than 'concrete' because she is spontaneous, flexible and does not always conform to traditions, habits or societal norms. Finally, she is an 'external' person because she is action-oriented and seeks energy from her environment and people. Based on the summation of these traits, as they are operationalized across the wheels that comprise the Design Powers System, Mary is categorized as a Storyteller.

Building on multiple trait-based theories, such as Carl Jung's Personality Types, the Myers-Briggs Type Indicator Model, and Keirsey's Temperament Theory - the four dominant design profiles represent four integrated configurations of design personality. These four configurations are distinct portraits of preferred creative motivations that cling together to create a "whole" depiction of an individual design student. The poetic titles of the four design profiles (Tinkerer, Dreamer, Storyteller, and Conductor) were created to capture the imaginations of students and promote the idea that each profile is crucial to the social dimension of the group. They are exaggerated representations of particular design-based traits, and are by no means intended to limit or define individual acuities or to prevent members from utilizing their other skills and bases of knowledge.

Ideally, the four dominant profiles are distributed across an equal number of team members, resulting in groups of four design students each. In alignment with the research in psychology and theories of collaboration 
described earlier in this piece, this approach intends to support the value of identifying individual strengths as part of building team synergy to produce more temporally efficient and conceptually effective design projects. By allocating distinct responsibilities to each group member of a given design team, the model stimulates shared ownership for project outcomes and addresses (and helps prevent) skill-duplication or redundancy between team-members as a means to increase the working efficiency of the entire group. Clarity of purpose enables each student to focus on a particular goal, with discrete competencies often dominating different stages of the design process. For example, in the initial stages of the project, the Dreamer will likely play a significant role in brainstorming ideas whereas, towards the end of the project, the Storyteller may direct the presentation of the final work.

\section{A Contextualized Description of the 16 Design Powers that} Result from Operating the Design Powers System

In addition to the four overarching dominant design profiles (Conductor, Storyteller, Tinkerer, Dreamer), the Design Powers System supports a detailed description of an individual design student's unique Design Power. Two main dualities - reason/intuition and empathy/pragmatism — serve as the core components of an individual student's design profile, and the two additional dualities of abstract/concrete and internal/external determine additional variations within the overarching profiles. This yields a total of 16 possibilities described as design powers (these are depicted in Figure 4). In other words, by operating the Design Powers System on behalf of a particular design student to pinpoint a unique cluster of skills, talents, values, and attitudes, as well as communication and interaction methods, a unique design power can be identified. Examining each of the 16 powers can provide insight into some individual design student's strengths, as well as more specific clues about how he-or-she might perform in a group.

Four possible design powers exist under each of the four distinct design profiles (these are also depicted in Figure 4), and while these might share similar core dualities, they differ with regard to how they describe attitudes toward the outside world. For example, a Wizard, Analyst, Developer and Director all fall under the design profile of Conductor because their core dualities ('reason' and 'pragmatism') describe them as practical, detail oriented, analytical and logical. However, a Director is external and concrete, and therefore, may be 


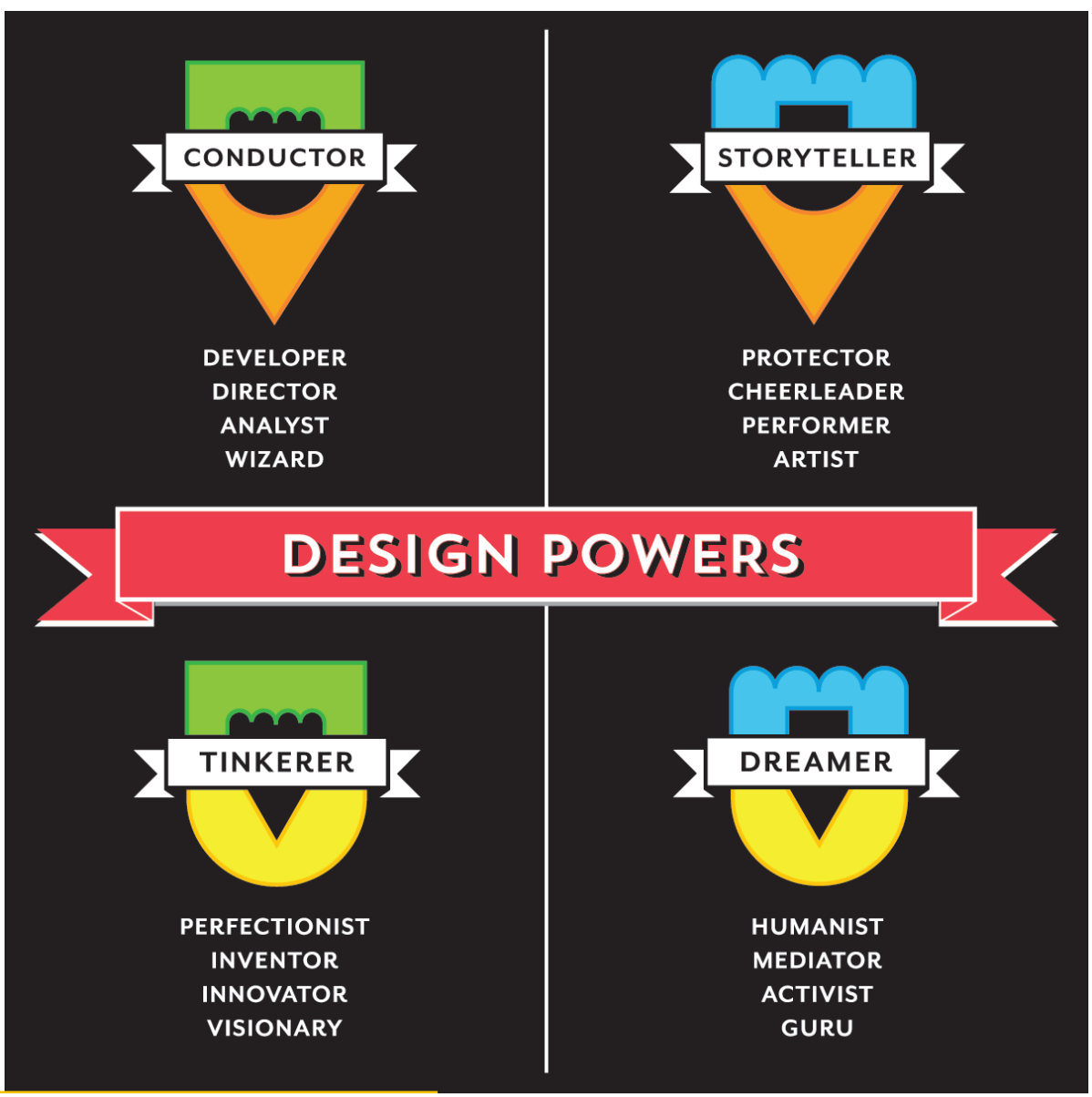

FIGURE 4: Each of the four dominant design profiles - Conductor, Storyteller, Tinkerer, and Dreamer - correlates with a group of four distinct design powers.

more suited to fulfill a role as an art director or a manager, while a Wizard is internal and abstract and may prefer to work as a programmer or developer.

While a detailed description of all 16 of these variations is beyond the scope of this paper, the following section provides an overview of the various classroom-based activities used to determine the four dominant design profiles and the 16 design powers that correlate with them.

\section{A Description of the Operation of the Design Powers System}

The operation of the Design Powers System constitutes three activities that progressively increase in complexity and structure. Each of these is centered on the identification of an individual design student's personality traits. By revealing a configuration of creative preferences, the three activities offer design faculty multiple entry points to help students build self-awareness and work in groups. Using one, or all, of the activities outlined below is an opportunity to help students take ownership of their unique combination of creative 


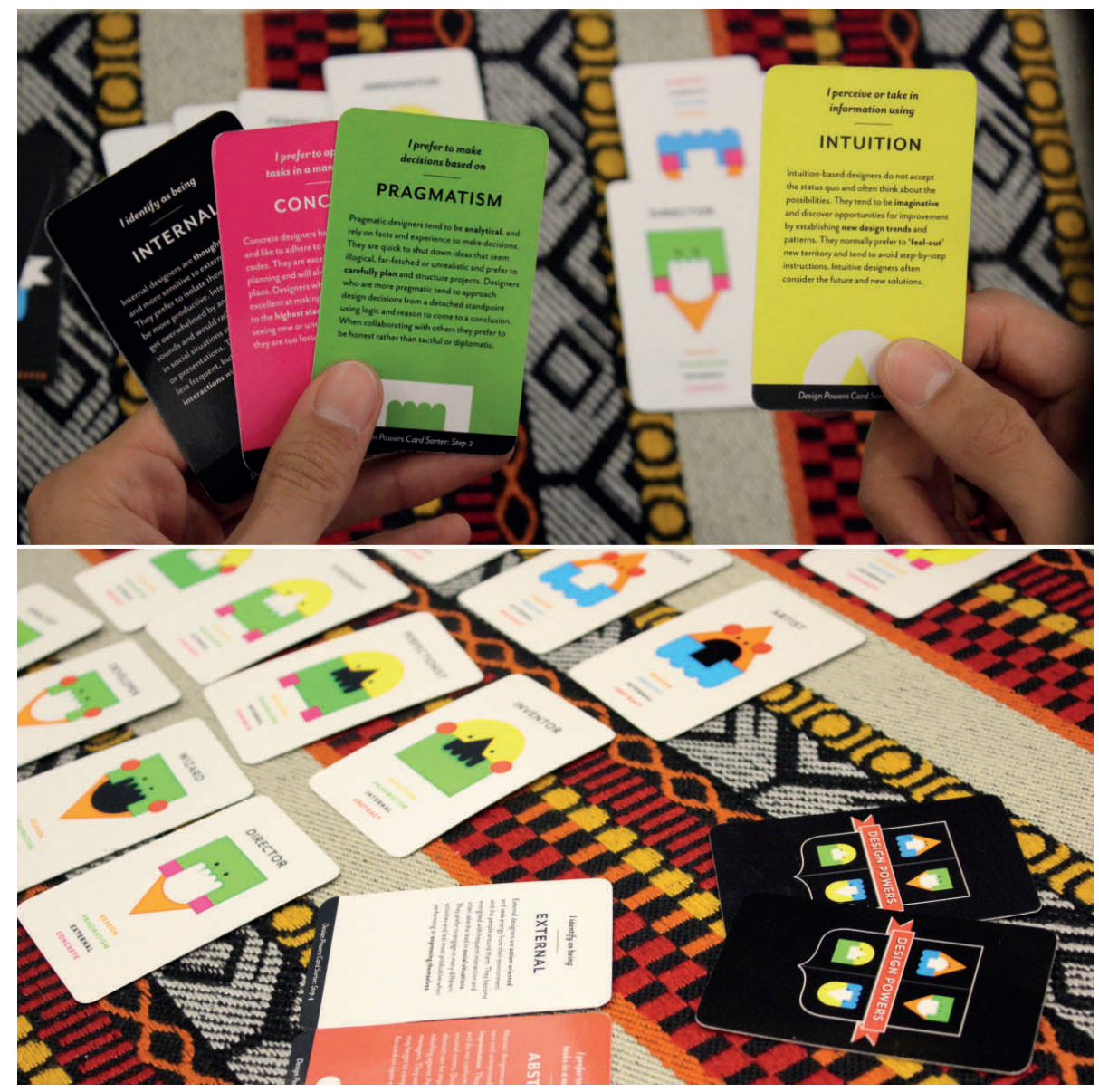

FIGURE 3: Operating the Design Powers Card Sorter affords individual student designers an opportunity to engage in a concrete, interactive activity with a specific goal. Doing this helps them work through the process of utilizing the four sets of design dualities to identify the specific design power from the group of 16 that is most applicable to them.

motivations to promote self-discovery and the accrual of a higher level of personal insight. These activities are often integrated into the preliminary phases of a collaborative project to familiarize the team with each member's acuities before they begin their design process together.

\section{Activity One: Utilizing Discussion to Facilitate Self Identification}

The first, and perhaps most simple of the three activities entails each student self-identifying with one of the four dominant design profiles: Conductor, Storyteller, Tinkerer and Dreamer (depicted in Figure 4). The activity is structured to extract, through conversation, observable dominant design preferences in individual design students. By introducing each of the four profiles through discussion, the in-class activity highlights how each dominant profile shapes 
an individual's role within a given group. As they engage in this activity, students discover where they fit on the design dualities continuum and participate in small group discussions about how their dominant traits align with their personal proclivities. While the four dominant profiles are not meant to serve as comprehensive, all-encompassing descriptions of a given design student's self-perception, they should resonate with him-or-her.

\section{Activity Two: Operating the Design Powers Card-Sorters}

The next evolution of the design profiles and design powers identification process is to utilize the Design Powers Card-Sorter as a fun and effective way to engage design students in identifying and realizing their uniquely personal means for engaging in design decision-making processes. The card deck that the authors created to operate the Design Powers Card-Sorter offers an interactive method to physically sort through the different design dualities inherent in the Design Powers Wheel using an "either-or" scenario (Figure 5). The cards are designed to help students make a choice between the design dualities that occupy each end of the spectrum, with each 'player' placing their choice "face up.” This card sorting activity eventually reveals one of the 16 Design Powers. By identifying their personal proclivities (based on how a given individual design student prefers generally to think and act), the designer uncovers his-orher unique power, such as Cheerleader. The card deck is sorted in the following order:

Step 1: Reason or Intuition

Step 2: Empathy or Pragmatism

Step 3: Concrete or Abstract

Step 4: Internal or External

\section{Activity Three: Operating the Design Powers Questionnaire}

The final, and more detailed activity of the Design Powers System is the Design Powers Questionnaire. This is a comprehensive method of analysis developed by the authors to help student designers identify their individual Design Power, from the group of 16. Much like questionnaires developed to assess personality by Myers-Briggs and Keirsey, this method of personality identification helps students discover their unique design preferences and motivations.

Administered as part of a classroom-based activity, design students choose their level of agreement or disagreement, on a 5-point Likert scale, in 
response to statements that capture the intensity of their attitudes towards various design-related scenarios. When administering the questionnaire, faculty should encourage design students not to provide any "neutral" answers and, instead provide their most typical response or feeling to the situation posed in the prompt or question (see the bulleted items in the "Sample Statements" section below). The questionnaire utilizes a series of statements measuring the four design dualities (reason/intuition, empathy/pragmatism, concrete/abstract, internal/external) that result in one of 16 design powers. The final score is calculated based on the following range: $1=$ disagree, $2=$ slightly disagree, $3=$ neutral, 4=slightly agree and 5=agree.

Sample statements include:

- You are obsessive about checking Rotten Tomatoes for ratings before you see a movie.

- Your friend fell and broke her leg, and the first thing you ask is "How?" rather than "Are you OK?"

- You think that everyone's views should be respected regardless of whether they are supported by facts.

- You like to read and follow instructions before trying to put a new piece of furniture together.

\section{Faculty Observations and Student Reflections about Operating the Design Powers System to Affect Group Design Work}

In the experience of the authors, group design work is sometimes viewed by graphic design students as an exceptional task that is unfair to some members of the team. In these instances, students take issue with what they define as an unequal distribution of the workload, varying levels of commitment by team-members, and biased assessment by faculty. In the anonymous surveys administered by the two faculty at the onset of this study, some students expressed hesitation about engaging in teamwork, noting that their previous experiences with team-based projects felt unproductive. One student also noted that she took the backseat during group projects due to predominating personality dynamics that she felt oppressed her ability to express her views. In light of these concerns, the Design Powers System was developed and tested in a range of graphic design courses over a three-year period, involving approximately 80 students located at Virginia Commonwealth University School of the Arts in Qatar. The cumulative findings indicate that facilitating acuity-based 
group creation as a team-building activity has the potential to improve communication among student design teams, bring students together around commonly identified, project-centric goals, and increase productivity.

The two faculty who formulated and operated this study observed that without the Design Powers System activities to guide group formation and operation, students were naturally drawn to their peers who possessed similar competencies, rather than to those who possessed competencies and skills that were complementary to their own. The system's emphasis on diversity helped prevent skill-duplication and allowed for a more balanced distribution of strengths within the group. Because the Design Powers System prioritized group decision-making, each student contributed equally to overall design decisions, but, at the same time, participated in the project according to their particular creative preferences. Students learned to depend on each other in more-orless equal degrees as they realized how individual behaviors exhibited by some, directly and indirectly, influenced others. For instance, at the beginning of the project, the Dreamer and Tinkerer often guide out-of-the-box thinking and playful generation of creative ideas.

Moreover, the identification of a specific role for each individual helped students to better navigate areas of discord and potential conflict by recognizing when a team-member was acting in alignment with his-or-her design profile. For instance, one student felt that her occupation of leadership roles (during previous group projects) unfairly forced her to push along classmates. However, identifying as a Conductor helped her build confidence in her leadership qualities, while her team-members became more aware of and gained more understanding about the purpose of her management role. At the same time, this explicit role enabled another team-member to not feel "slighted" by the leadership power dynamic that sometimes manifests in this personality.

Leading the process was both challenging and rewarding, with both of the faculty members who designed and led the study needing to remain sensitive to student perceptions that one of the four distinct design profiles was potentially more, or less, valuable than another. Other challenges included students' attempts to resist, or control, the process. In one case, students self-identified with a false Design Power to create a group composed of friends, with clashing strong personalities and ambitious goals that culminated in conflict. The challenges of group dynamics increased when language barriers created communication obstacles, with an opportunity for cultural exchange ending 
in perceptions of isolation and frustration for one team-member. But beyond a few isolated incidents that resulted in some negative perceptions of collaboration, the two faculty members observed how the correct identification of a Design Power could serve as a powerful tool to guide teamwork. When introduced at the initial stages of a project, it proved to be a fun and engaging activity that boosted students' confidence and sense of purpose in terms of their design work in collaborative teams.

\section{Limitations Inherent in the Structure of this Research}

The Design Powers System is intended for use within a collaborative design framework and, despite promising findings, the study is limited in some key ways. First, the collaborative component of the study restricted teams to an equal distribution of design profiles and team-members. Future research will investigate the expansion of groups as part of a strategy to support projects that require greater use of a single competency. For instance, two Tinkerers might discover or invent the means to overcome a technical hurdle through extensive, experimental making, while two Dreamers might increase the number of 'big ideas' needed to address and effectively resolve a given design challenge. Two-person teams embedded within groups of five or six students might serve as mini-think tanks, helping to spur shared creativity.

Another limitation to the study was its locale. The research was conducted and tested within a single University in one region in one Middle Eastern country and occurred within a conventional graphic design curriculum. To be accurately assessed, the methodology utilized to facilitate the Design Powers System will eventually need to be operated and assessed in multiple classroom environments, across diverse types of curricula, and within a varied array of institutions of higher learning. While the Design Powers System addresses the development and refinement of personal creative preferences, bases of knowledge and skills needed for successful collaboration; contextual and geographic differences could produce unanticipated effects or result in unexpected successes or failures of the model. As is the case with many types of qualitatively guided approaches to design research, achieving a high level of external validity is not possible, but it should also be understood that this could be an impediment to implementation.

The next phase of this research will address the original study's limitations by calling for design educators to participate in user-testing and patterning in different types of university-level design education settings to 
evaluate the efficacy of the methodology across a wider spectrum of design learning environments. The integration of a measurement method as this next phase is operationalized could also help faculty assess particular collaborative components, operational dynamics, and relative strengths and weaknesses that may develop as a result of the interactions within a team (or as a result of contextual factors surrounding the team) that could affect its functionality. These include but are not limited to the social, economic and technological environments within which a given team operates.

Finally, the Design Powers Questionnaire should not be used to analyze, evaluate or comment on the personality-based weaknesses and strengths of individual design students. Instead, the aim of utilizing this instrument is to learn from the psychological approaches and the theories of collaboration described in this discourse to produce an accessible and useful tool for use in design environments in a variety of educational contexts. Moreover, utilizing the analogue format of the Design Powers System as a worksheet or card-deck has the potential to skew results, enabling participants to identify a given role for themselves or others by manipulating the process. Future versions of the Design Powers System could benefit by being operationalized through digital mediums to produce randomized ordering and to provide immediate feedback to designers without biasing key aspects of its use.

\section{Future Directions and Implications for Further Development and Testing of the Design Powers System}

Conceived to dispel the myth of the one-size-fits-all designer, the Design Powers System celebrates the value of both individual talent and diverse team-membership. Recognizing how personality (and the traits and temperaments that affect it) shape interactions between collaborators has practical implications for the facilitation of design education at the undergraduate and graduate level. The approach can serve as a guide for design educators to identify student acuities and to facilitate collaboration between different types of learners in design classrooms. Research attests to the capability of small groups, comprised of individuals who possess blended complementary skills, to effectively tackle complex projects. Guiding students to discover their strengths by de-emphasizing competition can also improve the overall productivity and effectiveness of teams. Accordingly, individuality and difference should not be viewed as sources of contention, but instead, celebrated as necessary for group success. 
Encouraging emerging designers to better understand themselves and their design process through the assessment of design-based preferences offers the potential for team-members, including those who are working across disciplinary boundaries, to see design as a richly informed, deeply probative discipline with multiple facets for affecting change. The act of naming the diverse and extensive characteristics designers possess could bridge the persistent divide between the public's understanding of design and the capacity of designers to contribute to all aspects of a project's ideation, development, and resolution. Moreover, recognizing the diverse capacity of designers to contribute their ways of working and thinking across a wider variety of modes and mediums could expand preconceived notions about design research and processes. In other words, it could help dispel the myopic assumption that design is simply a service profession, associated with the digital execution of files. This may also help sensitize those outside of design, to recognize the contributions designers could make to socially and critically relevant projects that require inter-and-even-transdisciplinary collaboration. These implications support a complex, collaborative, and nuanced view of the design discipline that aims to fulfill more responsive social, environmental, and cultural purposes.

\section{References}

Barnbrook, J. et al. “First Things First Manifesto 2000.” AIGA Journal of Graphic Design, 17 (1999): p. 2.

Baxter Magolda, M.B. Making Their Own Way: Narratives for Transforming Higher Education to Promote Self-Development. Sterling, VA, USA: Stylus Publishing, 2004: pgs. 7-12.

Boekraad, H., and J. Smiers. "The New Academy." European Journal of Arts Education 2, no. 1 (1998): pgs. 60-65.

Boney, P. True Tilt: An Uncommon Quest. Bloomington, IN, USA: Author House, 2010.

Buchanan, R. "Human-centered design: Changing perspectives on design education in the East and West." Design Issues, 20.1 (2004): pgs. 30-39.

Buchanan, R. “Wicked Problems in Design Thinking.” Design Issues, 8.2 (1992): pgs. 5-21.

"Comparison of Insights Discovery System to Myers-Briggs Type Indicator." pgs. 1-5. Online. Available at: http://www.inside-inspiration.com.au/ 
factsheets/insights-discovery-and-mbti-comparison.pdf (Accessed May 12, 2017).

Davis, M. et al. “AIGA Designer 2025: Why Design Education Should Pay Attention to Trends," AIGA Design Educators Community, 22 August, 2017. Online. Available at: https://educators.aiga.org/wp-content/ uploads/2017/08/DESIGNER-2025-SUMMARY.pdf (Accessed February 4, 2018).

Dong, A., Kleinsmann, M., \& Deken, F. "Investigating Design Cognition in the Construction and Enactment of Team Mental Models.” Design Studies, 34.1 (2013): pgs. 1-33.

Douglas, M. “A History of Grid and Group Cultural Theory.” University of Toronto, Toronto, Canada, 2007. Online. Available at: http://projects. chass.utoronto.ca/semiotics/cyber/douglas1.pdf (Accessed May 12, 2017).

Findeli, Alain., "Rethinking design education for the 21st century: Theoretical, methodological, and ethical discussion.” Design Issues 17.1 (2001): pgs. $5^{-17}$.

Friedman, K. “Models of Design: Envisioning a Future Design Education.” Visible Language, 46.5 (2012): pgs. 132-153.

Gibson, M.R. \& Owens, K.M. “Making meaning happen between 'us' and 'them': strategies for bridging gaps in understanding between researchers who possess design knowledge and those working in disciplines outside design." In The Routledge Companion to Design Research, edited by J. Yee and P. Rodgers, pgs. 386-399. Routledge, NY, NY, USA: 2015.

Gratton, L., \& Erickson, T.J. "Eight Ways to Build Collaborative Teams.” Harvard Business Review, November 2007. Online. Available at: https:// hbr.org/2007/11/eight-ways-to-build-collaborative-teams (Accessed May 12, 2017).

Heller, S., \& Talarico, L. "An Education Manifesto for Icograda" in Icograda Design Education Manifesto 2011, Taipei: International Council of Graphic Design Associations, edited by A.G Bennett \& O.

Vulpinari, 2011: pgs. 82-85. Online. Available at: http://www.ico-d.org/database/ files/library/IcogradaEducationManifesto_2011.pdf (Accessed May 12, 2017).

Hunt, J. "Icograda Design Education Manifesto" in Icograda Design Education Manifesto 2011, Taipei: International Council of Graphic Design 
Associations, edited by A.G Bennett \& O. Vulpinari, 2011: 86-89. Available at: http://www.ico-d.org/database/files/library/IcogradaEducationManifesto_2011.pdf (Accessed May 12, 2017).

Katzenbach, J., \& Smith, D. The Wisdom of Teams: Creating the High-Performance Organization. New Boston, MA, USA: Harvard Business Review Press, 2015 .

Keirsey, D. Please Understand Me II: Temperament, Character, Intelligence. Del Mar, CA, USA: Prometheus Nemesis Book Company, 1998.

Kolko, J. Wicked Problems: Problems Worth Solving: A Handbook \& A Call to Action. Austin, TX, USA: ac4d, 2012.

Patton, B., \& Downs, T. Decision-Making Group Interaction: Achieving Quality, 4th Edition. Boston, MA, USA: Pearson, 2002.

Peeters, M., van Tuijl, H., Reymen, I., \& Rutte, C. “The Development of a Design Behavior Questionnaire for Multidisciplinary Teams.” Design Studies, 28.6 (2007): pgs. 623-643.

Richardson, R., \& DeVaney, T. “The Development and Validation of a Personality Instrument to Increase Collaboration." Educational Research and Reviews, 3.4 (2008): pgs. 121-127.

Rock, D. "SCARF: A Brain-Based Model for Collaborating with and Influencing Others." NeuroLeadership Journal, 1.1 (2008): pgs. 44-52.

Rock, D., Davis, J., \& Jones, B. “Kill Your Performance Ratings.” Strategy+Business, 8 August, 2014. Autumn 2014, Issue 76. Online. Available at: http://www.strategy-business.com/article/00275?gko=c442b (Accessed July 19, 2017).

Rosen, E. The Culture of Collaboration: Maximizing Time, Talent and Tools to Create Value in the Global Economy. San Francisco, CA, USA: Red Ape Publishing, 2007.

Sawyer, K. Group Genius: The Creative Power of Collaboration. New York, NY, USA: Basic Books, 2008.

Tieger, P., Barron, B., \& Tieger, K. Do What You Are: Discover the Perfect Career for You Through the Secrets of Personality Type. New York, NY, USA: Little, Brown and Company, 2014.

“The Tilt Leadership Model: Conscious Leadership to Create Innovative Performance." Brainard Consulting, 2010: pgs. 1-16. Online. Available at: http://www.brainardconsulting.com/wp-content/uploads/2010/O2/ The-Tilt-Leadership-Model4.pdf (Accessed May 12, 2017). 
Turner, J., Oakes, P., Haslam, S., \& McGarty, C. “Self and Collective: Cognition and Social Context." Personality and Social Psychology Bulletin, 20.5 (1994): pgs. 454-463.

Van Leeuwen, J., van Gassel, F. \& den Otter, A. “Teaching Collaborative Design.” In Proceedings of the International Workshop on Construction Information Technology in Education, 7 September 2004 Istanbul, Turkey, 2004: pgs. 1-9.

Winterhalter, B. "ISTJ? ENFP? Careers Hinge on a Dubious Personality Test." The Boston Globe, 31 August 2014. Online. Available at: http://www. bostonglobe.com/opinion/2014/08/30/istj-enfp-careers-hinge-dubious-personality-test/8ptUGXhu6DndFdjCngcxSN/story.html (Accessed January 19, 2017).

\section{Biographies}

Denielle Emans, an Associate Professor at Virginia Commonwealth University School of the Arts in Qatar, has spent 14 years navigating a diverse career path between research and design in higher education and practice. She is passionate about bringing social innovation and intercultural communication together to fuel creative action. Professor Emans' principal area of concentration involves investigating and analyzing participatory and collaborative design methods, with attention to the inclusion of diverse voices as part of the planning and operationalization of the design process. She is currently a Ph.D. Candidate at the Centre for Communication and Social Change at the University of Queensland in Brisbane, Australia. She holds a Master's degree in Graphic Design from North Carolina State University's School of Design and a Bachelor of Arts in Communications from the University of North Carolina, Chapel Hill. (djemans@vcu.edu)

Basma Hamdy is a research-based designer, author and educator producing work that explores historical, political and social issues. Her book Walls of Freedom: Street Art of the Egyptian Revolution, written in collaboration with Don Karl, was published in March 2014 (Berlin, Germany: From Here to Fame Publishing). She is currently working on her second book Khatt: Egypt's Calligraphic Landscape (London, UK: Saqi Books; to be published in October 2018). Professor Hamdy earned an MFA from the Maryland Institute College of Art and is 
a Ph.D. candidate at PhDArts: Leiden University and The Royal Academy of Art (KABK), The Netherlands. She has taught at the University level for over 14 years and is currently an Associate Professor of Graphic Design at Virginia Commonwealth University School of the Arts in Qatar.

(bwhamdy@vcu.edu) 